Mens

revue d'histoire intellectuelle de l'Amérique française

Phillip Buckner, dir. Canada and the End of Empire.

Vancouver, UBC Press, 2005. 328 p.

\title{
Jean-François Constant
}

Volume 7, numéro 2, printemps 2007

URI : https://id.erudit.org/iderudit/1024133ar

DOI : https://doi.org/10.7202/1024133ar

Aller au sommaire du numéro

Éditeur(s)

Centre de recherche en civilisation canadienne-française

ISSN

1492-8647 (imprimé)

1927-9299 (numérique)

Découvrir la revue

Citer ce compte rendu

Constant, J.-F. (2007). Compte rendu de [Phillip Buckner, dir. Canada and the

End of Empire. Vancouver, UBC Press, 2005. 328 p.] Mens, 7(2), 341-346.

https://doi.org/10.7202/1024133ar d'utilisation que vous pouvez consulter en ligne.

https://apropos.erudit.org/fr/usagers/politique-dutilisation/ 
de soldat a brisé l'élitisme traditionnellement lié au tabagisme et ouvert la porte à la distribution à grande échelle des produits du tabac. Il ne serait toutefois pas avisé de sous-estimer le rôle de la guerre dans le développement de la société de consommation au $\mathrm{XX}^{\mathrm{e}}$ siècle.

Aussi, ce qui manque vraiment à l'étude de Rudy est une analyse plus poussée de la relation entre le consumérisme et le libéralisme. Le libéralisme n'était pas statique durant la période étudiée. Des idéaux de John Stuart Mill à ceux de John Maynard Keynes, il a connu plusieurs mutations. Rudy évoque cette transition, mais sans l'expliquer, malgré le fait que les habitudes de consommation de tabac semblent la réfléchir. Qu'à cela ne tienne. The Freedom to Smoke demeure un excellent ouvrage qui est bien écrit, bien argumenté et qui suggère de nouvelles pistes de recherches pour les historiens au Canada. Bien que Rudy ne soit pas allé au bout des questions que suscite son étude, il a quand même en main quelques réponses.

Alan Gordon Département d'bistoire University of Guelph

Traduction : Michel Ducharme

\section{Phillip Buckner, dir. Canada and the End of Empire. Vancouver, UBC Press, 2005. 328 p.}

L'ouvrage collectif Canada and the End of Empire se veut un plaidoyer en faveur d'une réinterprétation de la dimension impériale de l'expérience historique canadienne et de sa réinsertion dans l'historiographie. Cette dernière a étonnamment 
négligé le renouveau historiographique des imperial studies qui vise à redéfinir les rapports de force et les influences réciproques des colonies et de la métropole britannique, notamment sur les plans culturel et identitaire, au-delà de l'existence formelle de l'empire britannique. Le directeur de l'ouvrage, Philip Buckner, n'en est d'ailleurs pas à sa première critique de l'historiographie canadienne-anglaise ("Limited Identities" Revisited: Regionalism and Nationalism in Canadian History", Acadiensis, 2000) ni à son premier plaidoyer en faveur d'une réinterprétation de celle-ci tenant compte de l'importance de la dimension impériale de l'histoire canadienne, surtout au $\mathrm{XIX}^{\mathrm{e}}$ siècle ("Whatever Happened to the British Empire", Journal of the Canadian Historical Association, 1993 ; «Was there a "British" Empire? The Oxford History of the British Empire from a Canadian Perspective", Acadiensis, 2002). Cette foisci, Buckner et ses collaborateurs s'attaquent à l'idée reçue selon laquelle le lien impérial unissant le Canada et la GrandeBretagne, tant sur les plans politique et économique qu'intellectuel et culturel, se détériore rapidement après la Première Guerre mondiale pour favoriser tantôt l'émergence d'un sentiment national distinct, tantôt une plus grande intégration du Canada à la sphère économique et culturelle états-unienne. $\mathrm{Au}$ contraire, pour les auteurs de Canada and the End of Empire, le lien impérial persiste au-delà de la Deuxième Guerre mondiale, jusqu'à la décennie 1970 en fait, et son étiolement ne se fait pas sans heurts. La persistance de la dimension britannique de l'identité nationale au Canada anglophone, les efforts des élites politiques, culturelles et intellectuelles pour maintenir les traditions intellectuelles et artistiques britanniques face à une américanisation croissante de la culture populaire, de même que les efforts du gouvernement Diefenbaker, entre autres, pour accentuer les échanges commerciaux entre les deux pays, témoignent selon les auteurs de la pré- 
sence significative d'une dimension impériale au sein de la société canadienne de l'après-guerre.

Tout d'abord, une légère précision s'impose. Cet ouvrage concerne surtout, voire presque uniquement, les attitudes et les réactions de Canadiens d'origine britannique face au déclin du lien impérial entre la Grande-Bretagne et le Canada suivant la Deuxième Guerre mondiale. Hormis le chapitre de J. R. Miller sur le lobbying londonien des Premières Nations, les textes traitent avant tout du déclin et de l'éventuelle disparition du Canada "britannique ". Canada and the End of Empire ne constitue pas pour autant une apologie du colonialisme britannique ni un ouvrage de nostalgie mémorielle, loin s'en faut. Plusieurs textes démontrent de façon concluante la persistance du lien impérial britannique sous une forme ou une autre, lien souvent et peut-être volontairement ignoré par les études de la période d'après-guerre.

Bien que l'effort de réinterprétation soit louable, il demeure que les dix-huit textes rassemblés par Buckner ratent leur cible, pour autant que cette cible soit un certain renouveau de la pratique historienne des canadianistes. Quelques textes sont fort intéressants et poussent effectivement le lecteur à reconsidérer la dimension impériale de l'expérience canadienne à la suite de la Deuxième Guerre mondiale, mais plusieurs autres, redondants ou répétitifs, de même que l'absence ou l'omission de certains thèmes rendent parfois la lecture de l'ouvrage frustrante.

L'absence d'une analyse de la dimension québécoise du sujet apparaîtra injustifiable aux yeux de plusieurs, avec raison. Les quelques lignes accordées ici et là à l'opinion publique québécoise et à la spécificité culturelle du Québec à l'intérieur de textes portant sur d'autres sujets témoignent soit d'un manque d'intérêt, soit de connaissances insuffisantes. La raison invoquée par Buckner pour justifier cette lacune (le 
refus des historiens québécois de participer à l'ouvrage) est à cet égard peu convaincante. Il en résulte une analyse trop succincte de la particularité culturelle québécoise qui pousse Allan Smith, entre autres, dans un texte autrement solide et captivant, à faire une généralisation grossière quant au bouillonnement culturel du Québec après 1945. Smith, en effet, n'y voit qu'une réorientation salvatrice des élites intellectuelles et culturelles vers la France, ignorant totalement l'émergence d'une culture populaire propre au Québec et à sa commercialisation croissante. Pourtant, le très bon texte écrit par José Igartua sur "l'autre » Révolution tranquille, celle du Canada anglophone, démontre clairement l'avantage d'inclure l'expérience québécoise dans l'analyse plus globale de la fin de l'empire. Selon Igartua, le Canada anglophone vit sa propre révolution culturelle après la Deuxième Guerre mondiale. La crise de Suez devient alors l'événement clé autour duquel s'articulent et se confirment la désintégration du Canada «britannique » et l'émergence d'une identité nationale typiquement canadienne.

Tout aussi absente est une analyse plus globale de la question. Pourquoi ne pas avoir cherché à comparer l'expérience canadienne à celle d'autres pays ayant eux aussi vécu un déclin du lien impérial à la même époque ? Il aurait été fort intéressant de connaître l'expérience d'autres anciens dominions à la même époque, telles l'Australie et la NouvelleZélande, afin de mieux différencier les facteurs qui font la spécificité du Canada (rapport commercial avec les États-Unis, nationalisme québécois) des facteurs directement reliés à la structure impériale ou à la situation intérieure de la GrandeBretagne (définition du rôle du Commonwealth, réorientation commerciale et politique vers l'Europe).

Malgré ces oublis, force est de constater que les textes traitant des dimensions culturelle et identitaire, qui représen- 
tent environ la moitié de l'ouvrage, sont fort intéressants et démontrent bien la présence continue de l'empire britannique dans l'imaginaire identitaire canadien-anglais. George Richardson analyse l'enseignement des sciences sociales et de l'histoire dans le système d'éducation albertain et ontarien et fait ressortir la promotion constante d'une identité canadienne britannique bien après 1945 . Sa critique psychanalytique de la crise psychique ("psychic crisis») qui caractérise l'enseignement de l'histoire au Canada anglais fera certes sourciller quelques historiens, mais l'argumentation et l'analyse demeurent solides. Paul Rutherford offre une analyse succincte de l'américanisation de la culture canadienne, celle-ci témoignant plutôt d'une dominance de la culture populaire («low culture »), de facture états-unienne, sur la culture élitaire (" high culture »), traditionnellement britannique. Philip Buckner nous rappelle quant à lui le rôle joué par la monarchie dans l'imaginaire identitaire canadien. Il soutient que la visite royale de 1959, la dernière visite royale de grande envergure selon lui, révèle une division croissante à l'intérieur de la société canadienne, non pas entre les Canadiens d'origine britannique et les autres, qu'ils soient Québécois, d'origine non britannique ou Amérindiens, mais plutôt entre, d'une part, une identité canadienne britannique marquée par la loyauté et un sentiment d'admiration vis-à-vis de l'empire et de la monarchie et, d'autre part, une identité davantage pluraliste reflétant mieux la composition de la société canadienne d'après-guerre.

L'autre moitié de l'ouvrage est consacrée à des textes à saveur plus politique, voire diplomatique, et économique. Malheureusement, les textes sont souvent trop courts pour permettre une analyse en profondeur du sujet, ce qui aurait pourtant été utile en ce qui a trait à l'analyse des échanges commerciaux du Canada avec les États-Unis et la Grande- 
Bretagne, ainsi que de la politique étrangère canadienne à leur égard. Hormis Steve Koerner, qui réussit à expliquer de manière convaincante que l'échec des tentatives de l'industrie automobile britannique de percer le marché canadien est dû autant à l'ignorance des producteurs britanniques des réalités de ce marché qu'à la concurrence américaine, la plupart des auteurs ne parviennent pas en une quinzaine de pages à remettre en question de façon stimulante les idées reçues sur les rapports commerciaux et politiques du Canada et de la Grande-Bretagne durant la période à l'étude.

Bref, malgré quelques bons coups qui témoignent de la pertinence d'accorder une plus grande attention à la dimension impériale de l'expérience historique canadienne et québécoise au $\mathrm{XX}^{\mathrm{e}}$ siècle - et l'on pourrait dire la même chose pour le XIX ${ }^{\mathrm{e}}$ siècle - plusieurs textes trop courts pour tirer une conclusion originale ou encore répétitifs empêcheront Canada and the End of Empire de devenir un ouvrage important dans l'historiographie canadienne-anglaise. L'appel lancé par les auteurs ne doit pas rester lettre morte, cependant. En effet, de nombreuses études restent à faire sur l'histoire des sociétés canadienne et québécoise d'après-guerre qui tiennent compte de leur appartenance passée à l'empire britannique et des effets de cette appartenance sur la conjoncture actuelle.

Jean-Francois Constant Département d'bistoire Université McGill 